\title{
Measuring and Mitigating Mercury Gases in the Museums Victoria Collection.
}

\author{
Danielle Measday $\ddagger$, Rosemary Goodall ${ }^{\ddagger}$ \\ ‡ Museums Victoria, Melbourne, Australia
}

Corresponding author: Danielle Measday (dmeasday@museum.vic.gov.au)

Received: 29 May 2018 | Published: 13 Jun 2018

Citation: Measday D, Goodall R (2018) Measuring and Mitigating Mercury Gases in the Museums Victoria

Collection. Biodiversity Information Science and Standards 2: e27044. https://doi.org/10.3897/biss.2.27044

\begin{abstract}
For the past six years the conservation and collection management departments at Museums Victoria have been conducting a major survey to determine the type and extent of hazardous substances in the collections to better inform safe handling and storage practices. This paper focuses on mercury compounds in the collection, including mercury chloride applied as a pesticide, mercury sulfide pigments, liquid mercury used in scientific equipment, and mineral specimens such as native mercury and cinnabar. All these compounds can release volatile mercury vapour into storage furniture and have the potential to contaminate both the cabinet and other specimens stored nearby.

Although previous testing had confirmed that the air in storage rooms and workspaces contained no detectable levels of mercury vapour, recent publications by Hawks et al. 2004, Havermans et al. 2015 and Marcotte et al. 2017 showing high levels of mercury vapour inside storage containers in herbaria raised concern that there could be higher than acceptable levels of mercury vapour building up inside storage cabinets at Museums Victoria. This prompted analysis of the headspace in cabinets using a Jerome $\mathrm{J} 405$ portable mercury vapour meter. Testing was informed by the results of previous hazards surveys using X-ray fluorescence spectrography to target cabinets where mercury vapour was likely to be present.
\end{abstract}

Air from cabinets was sampled across the indigenous cultures, history, technology and natural sciences collections. Results showed levels of mercury vapour could be 
considerably above $25 \mu \mathrm{g} / \mathrm{m}^{3}$ the Australian time-weighted average (TWA) exposure standard for an 8 hour workday in cabinets of bird skins and indigenous artefacts treated with mercuric chloride pesticides. Results above $150 \mu \mathrm{g} / \mathrm{m}^{3}$ the temporary emergency exposure level (TEEL) were measured in the mineralogy collection. Mitigation strategies are being implemented to reduce the risks to staff health and contamination of other collection materials, including enclosing mercury-containing species of minerals in gas barrier film, venting high risk cabinets to dissipate vapour before accessing specimens, and engineering controls during the handling of specimens.

\section{Keywords}

Conservation, hazardous substances, storage, natural science collections, mineralogy, vapour

\section{Presenting author}

Danielle Measday

\section{References}

- Havermans J, R.Dekker, Sportel R (2015) The effect of mercuric chloride treatment as biocide for herbaria on the indoor air quality. Heritage Science 3 (39): 1-8.

- Hawks C, Makos K, Bell D, Burroughs EG, Wambach PF (2004) An Inexpensive Method to Test for Mercury Vapor in Herbarium Cabinets. Taxon 53: 783-790.

- Marcotte S, Estel L, Minchin S, Leboucher S, Meur SL (2017) Monitoring of lead, arsenic and mercury in the indoor air and settled dust in the Natural History Museum of Rouen (France). Atmospheric Pollution Research 8 (3): 483-489. 